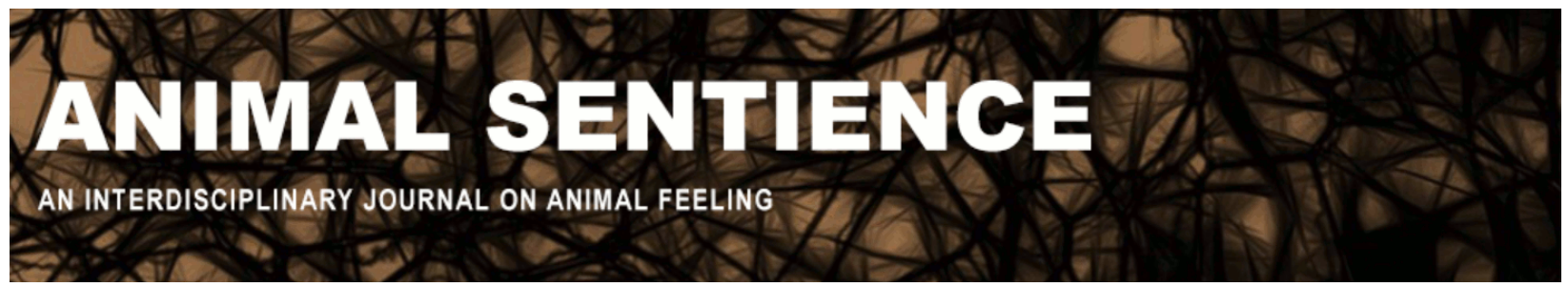

Martin, Allison L. (2017) The development and expression of canine emotion. Animal Sentience 14(10)

DOI: $10.51291 / 2377-7478.1261$

Date of submission: $2017-11-20$

Date of acceptance: 2017-11-27

(c)

This article has appeared in the journal Animal

Sentience, a peer-reviewed journal on animal

cognition and feeling. It has been made open access,

free for all, by WellBeing International and deposited

in the WBI Studies Repository. For more information,

please contact

wbisr-info@wellbeingintl.org.

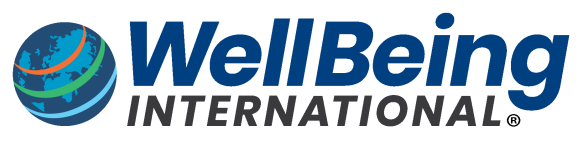

SOLUTIONS FOR PEOPLE, ANIMALS AND ENVIRONMENT 


\title{
The development and expression of canine emotion
}

\author{
Commentary on Kujala on Canine Emotions
}

\author{
Allison L. Martin \\ Department of Psychology \\ Kennesaw State University
}

\begin{abstract}
In her review of canine emotions, Kujala (2017) discusses how humans often attribute emotions such as fear, love, and jealousy to their canine companions. This attribution is often dismissed as anthropomorphism, suggesting that only humans can possess these emotions. I argue that emotions are not something we possess but features of certain behavioral patterns. Both human and canine emotions arise through evolution and conditioning; examining their development and expression may lead to new insights about both canine and human behavior.
\end{abstract}

\begin{abstract}
Allison L. Martin is Assistant Professor of Psychology at Kennesaw State University. Her research interests include applied behavior analysis, captive animal management, animal training, and animal welfare. psychology.hss.kennesaw.edu/facultystaff/allison-martin/
\end{abstract}

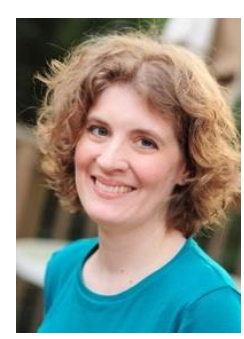

Kujala (2017) opens her review of canine emotion research by stating, "It is not possible to demonstrate that dogs (Canis familiaris) feel emotions, but the same is true for all species, including our own." This sentence raises several interesting points. What, exactly, are emotions, and what would it mean to demonstrate that an organism feels an emotion? Also, why do we (humans) accept the presence of emotions in ourselves but so often deny them in other species? I would imagine that I am not alone among animal researchers in feeling a disconnect. I consider the little brown dog curled up next to me to be a relatively clever, feeling organism. Yet, as a scientist, I find that much of the research on canine cognition and emotion falls short of my litmus test, with researchers drawing conclusions that are not fully justified by the data.

1. Emotions as Behavioral Patterns. What is it to feel an emotion? Kujala separates emotion into behavioral, physiological, somatic, and cognitive components. As a behaviorist, I argue that ascribing an emotion is primarily a description of a behavioral pattern. "You seem afraid," is a convenient and well-accepted shortcut for stating something like, "I saw you flinch, you are moving away from this stimulus, your eyes are scanning the environment, and what you are telling me suggests that you have been thinking about what bad things might happen in this situation." Some of these behaviors are private (thoughts) and some public (eye movements); some are voluntary (moving away), and some are involuntary (flinching). Even in humans, when we have the benefit of verbal report, the various expressions of emotion are often incongruent and 
difficult to measure (see, for example, Bradley \& Lang, 2000). When attempting to measure and categorize emotions in animals, the task becomes even more complex.

Despite the complexity, assignment of emotions is useful. If you can categorize a dog's behavioral pattern as fear, you instantly have a sense of what behaviors to expect from that dog and which environmental manipulations might reduce those behaviors. This is important for a variety of reasons, including bite prevention, the treatment of canine behavioral disorders, and training applications. We must be careful when we identify emotion as the cause of behavior though. In this sense, it is similar to a personality trait. Describing someone as an extrovert provides you with a relatively stable prediction of how they might react in various situations. However, it becomes circular when you list extroversion as a cause of the very behaviors that were used to define that individual as an extrovert. Similarly, while the behavior of a dog seeking proximity to its owner could be included in a set of behaviors we might label as love, crediting love as the primary cause of that behavior is, at best, incomplete.

2. The Development of Emotion. In his commentary on Kujala's target article, Zentall (2017) makes the point that one must always consider simpler alternative accounts. Both Kujala and Zentall point out areas in which methodological gaps have left open the possibility of alternative explanations for canine behaviors attributed to emotions such as inequity aversion, empathy, or altruism. However, I assert that the deeper issue is not only that there may be a simpler explanation for these behaviors in dogs, but that we are also failing to recognize the basic origins of these behaviors in ourselves.

For example, recent functional imaging studies have shown that the reward centers in dogs' brains are active when the dog smells a familiar human (Berns, Brooks, \& Spivak, 2015). While popular media outlets were quick to describe this as evidence that dogs love us (e.g., Fisher, 2014), Berns and colleagues were clear that while the results could indicate an emotional attachment to humans, the results could also be explained through conditioning (e.g., the owner being repeatedly paired with food). We (humans) have a tendency to view love (and other emotions) as something akin to an internal possession. As such, we wonder whether dogs possess that same kind of love. Using that framework, we fail to recognize that our own love is also the result of evolution and conditioning.

3. Phylogeny and Ontogeny of Emotional Expression. The development and expression of emotions will vary among species and individuals based on physiology (e.g., the ability to perceive stimuli) and the organism's evolutionary and ontogenetic history. For example, the existence of canine brain structures used to process both canine and human faces (as reviewed by Kujala) signifies that it is possible for dogs to use human facial expressions as social cues. In fact, dogs respond to human social cues even better than some primates (for review, see Hare \& Tomesello, 2005). Interestingly, selective breeding to reduce the emotion of fear toward humans may have facilitated this evolution. There is also evidence that this ability to respond to human social cues resulted from convergent evolution, whereby humans and domestic dogs were shaped through similar selective pressures (Hare \& Tomesello, 2005). Ontogeny is at least equally important though. Wolves socialized with humans actually outperformed domestic dogs at following a human pointing cue, and shelter dogs and pet dogs differed in performance on this task, highlighting the importance of rearing and environment in these behaviors (Udell, Dorey, \& 
Wynne, 2008). Humans shape the expression of emotion in dogs both through selection (e.g., dogs that exhibit an inner eyebrow raise are adopted faster from shelters than those that do not; Waller et al., 2013) and through the reinforcement of individual behaviors (e.g., giving social attention in response to a dog resting its head on your chest). The role of selection, rearing, and environment in the expression of emotion in dogs is an area ripe for future research.

4. Conclusion. Kujala's review is a thoughtful synthesis of the research on canine emotions from a variety of disciplines. As we advance this field, we should examine how the expression of emotion has been shaped by evolution and experience. The domestic dog, with its evolutionary history and close association with humans, provides an intriguing model for this investigation. A better understanding of the expression of emotion in dogs also has important applications in improving the lives of both dogs and dog owners. I agree with Kujala that taking a unified approach to the expression of emotion in both humans and animals may lead to new insights, and that advances in technology and methodologies have the potential to bring us closer to understanding the expression of emotion in animals.

\section{References}

Berns, G. S., Brooks, A. M., \& Spivak, M. (2015). Scent of the familiar: An fMRI study of canine brain responses to familiar and unfamiliar human and dog odors. Behavioural Processes, 110, 37-46.

Bradley, M. M., \& Lang, P. J. (2000). Measuring emotion: Behavior, feeling, and physiology. In R. D. Lane \& L. Nadel (Eds.), Cognitive Neuroscience of Emotion (pp. 243 - 276). New York: Oxford University Press.

Fisher, T. (2014, November). Brain scans reveal what dogs really think of us. Mic.

Hare, B., \& Tomasello, M. (2005). Human-like social skills in dogs. Trends in Cognitive Sciences, 9, 439-444.

Kujala, M. V. (2017). Canine emotions as seen through human social cognition. Animal Sentience 14(1).

Udell, M. A. R., Dorel, N. R., \& Wynne, C. D. L. (2008). Wolves outperform dogs in following human social cues. Animal Behaviour, 76, 1767-1773.

Waller, B. M., Peirce, K., Caeiro, C. C., Scheider, L., Burrows, A. M., McCune, S., \& Kaminski, J. (2013). Paedomorphic facial expressions give dogs a selective advantage. Plos One, 8(12), 16.

Zentall, T. R. (2017). The study of emotion in animals. Animal Sentience 14(3). 